\title{
DECOMMISSIONING OF A CAESIUM-137 SEALED SOURCE PRODUCTION FACILITY
}

\author{
A. Murray \\ RWE NUKEM Limited \\ B424 Harwell International Business Centre, Oxon OX11 8QJ United Kingdom \\ H. Abbott \\ Amersham plc \\ Amersham Laboratories, White Lion Road, Amersham, Bucks HP7 9LL United Kingdom
}

\begin{abstract}
Amersham owns a former Caesium-137 sealed source production facility. They commissioned RWE NUKEM to carry out an Option Study to determine a strategy for the management of this facility and then the subsequent decommissioning of it.

The decommissioning was carried out in two sequential phases. Firstly robotic decommissioning followed by a phase of manual decommissioning.

This paper describes the remote equipment designed built and operated, the robotic and manual decommissioning operations performed, the Safety Management arrangements and summarises the lessons learned.

Using the equipment described the facility was dismantled and decontaminated robotically. Some $2300 \mathrm{~kg}$ of Intermediate Level Waste containing in the order of 4000Ci were removed robotically from the facility. Ambient dose rates were reduced from 100's of R per hour $\gamma$ to 100's of mR per hour $\gamma$. The Telerobotic System was then removed to allow man access to complete the decommissioning. Manual decommissioning reduced ambient doserates further to less than $1 \mathrm{mR}$ per hour $\gamma$ and loose contamination levels to less than $0.25 \mathrm{~Bq} / \mathrm{cm}^{2}$. This allowed access to the facility without respiratory protection.
\end{abstract}

\section{INTRODUCTION}

RWE NUKEM accepted on a turnkey basis a contract to decommission a Caesium-137 sealed source production facility owned by Amersham. The facility consisted of eight glass-fibre containment boxes and a single fabricated steel material entry/exit box (see Figure 1). Up to 175 $\mathrm{mm}$ of lead shielding was provided along the working face of the facility to minimise operator dose uptake. When the plant was operational materials and equipment inside the cell line were manipulated with tongs that passed through the front working face. Each cell was connected to its immediate neighbour by a $275 \mathrm{~mm}$ diameter tunnel that was used for inter box transfers. The boxes were supported on a steel and concrete plinth.

The cell line was used to manufacture encapsulated 137Cs pellets for 13 years. The caesium was supplied either as a solution, a powder or in pellet form and subjected to various processes 
including wet chemistry before conversion into small ceramic sources. The sources were then encapsulated in stainless steel capsules and shipped to customers. The finished capsules could be as small as $4 \mathrm{~mm}$ diameter and $8 \mathrm{~mm}$ long containing $2 \mathrm{Ci}(75 \mathrm{GBq})$ of activity. The pellets were smaller often $2 \mathrm{~mm}$ diameter and $2 \mathrm{~mm}$ long. Given the need to manipulate the in cell equipment using tongs alone, spillage of capsules, pellets and liquid stock was a significant possibility. Spilt materials were difficult to recover and could pass into areas that were difficult to see and reach with the tongs.

When manufacturing ceased in 1991, the facility was put on a programme of care and maintenance and the shielded cells used for the temporary storage of the remaining waste. With the passage of time the high radiation dose rates caused the fibreglass and perspex used in the construction of the inner cells and the plastic ventilation system to deteriorate.

Amersham therefore invited RWE NUKEM to undertake an Option Study in 1993 to determine the optimum strategy for the future management of the facility.

At the time the Option Study was carried out the following facts were clear.

- The facility was located adjacent to other working plant and the need to keep this plant operational would constrain the lay out and size of any equipment provided to facilitate the decommissioning.

- There was a large volume of caesium-contaminated waste and part finished sources inside the facility. Dose rates of the order of $3000 \mathrm{R} / \mathrm{h} \gamma$ have been measured on some of these items and significant quantities of activity of the order of $4000 \mathrm{Ci}$ have been removed from the facility.

- The associated radiation levels had damaged the facility local ventilation system and the box containment.

- The radiation levels inside the maintenance corridor were such that man entry was impossible and consequently it was impossible to repair the ventilation system.

- The radiation had also damaged the internal seals on the tongs and crazed the viewing panels on the boxes. This made it impossible to use the tongs to manipulate the waste and made it difficult to see into many of the boxes.

- Although small access ports existed in three of the cells their size and the high radiation levels precluded their use for waste removal operations.

- Whilst the "plug" door was effective as a shield door it could not be used as a means of access during the initial decommissioning operations.

Four options were considered for the facility.

1. Carrying out the minimum work necessary to enable an appropriate care and maintenance regime to be instituted.

2. To refurbish the existing equipment and then to undertake early post operational clean out but delay final (remote) dismantling of the facility. 
3. To refurbish the existing equipment and then use it to undertake the clean out and to follow this by completing the waste removal and the dismantling of the facility using advanced remote handling techniques.

4. To undertake post operational clean out and the dismantling of the facility using advanced remote handling techniques.

Option 4 was the preferred approach.

The overall objective of the work was to decommission the facility in a safe and cost effective manner. The physical end point was the complete removal of the facility leaving only the decontaminated areas that form part of the building structure. The target Radiological End Point was $40 \mathrm{~Bq} / \mathrm{cm} 2$. The actual decommissioning itself involved two basic phases, a remote phase followed by a manual one. The aim of the remote phase being to reduce the local dose rates to the lowest practically achievable level and to minimise the amount of manual work that has to be carried out.

\section{REMOTE DECOMMISSIONING EQUIPMENT}

The Decommissioning Plan followed directly from the Option Study. It confirmed that to complete the work it would be necessary to provide an extended primary containment together with a remote waste posting facility, a new ventilation system, a new secondary containment and a Telerobotic System to undertake the actual work. This work started in 1995 with detailed design and commissioning was completed by 1997.

\section{The Primary Containment and its Ventilation Plant}

The primary containment and shielding was provided, with the exception of the west wall, by parts of the original structure of the building in which the facility is located. The Maintenance Bay and the Waste Posting Facility completed the primary containment, as shown in Figure 1.

The Waste Posting Facility was used to transfer waste out of the facility remotely. Previously manual posting was the only option for inserting and removing materials. This was not suitable for decommissioning waste. Waste cans filled by the Telerobotic System would be brought back here for radiological monitoring before posting out remotely and handing over to Amersham for collection and safe long-term storage. These operations were carried out using tongs through a $100 \mathrm{~mm}$ lead wall. Viewing was through a lead glass window.

The Maintenance Bay had two primary purposes. Both required the sliding shield door, which had replaced the original plug door, to be closed. The Maintenance Bay provided a low dose area where the Telerobotic System could be stored when not in use. Its demountable lead wall also allowed access to the Telerobotic System if maintenance was required on it.

The Maintenance Bay and Waste Posting Facility were constructed from a combination of lead, Perspex and mild steel assembled on steel frames to form a single shielded enclosure.

The original Primary Ventilation system was not performing as it should, radiation had damaged the plastic ducting, which had collapsed and fallen onto the floor in places. A new ventilation 
system had to be installed. It was connected into a posting port at cell nine at one end of the facility. Doserates from this port were $200 \mathrm{R} / \mathrm{h} \gamma$.

Once the new ventilation system was installed and commissioned, the original ventilation system that served the primary containment was isolated, sealed and removed.

The New Ventilation System produce an air velocity of at least $0.5 \mathrm{~m} / \mathrm{s}$ through all known openings in the facility and a small depression relative to the secondary containment. It protects the operators by drawing air from the secondary containment into the facility through filtered air inlets in the Waste Posting Facility and cells 1-3. This air flows through the facility, is collected from cell 9. A pre filter was installed in the port at cell 9. The air then passed through two stages of High Efficiency Particulate Air (HEPA) filtration to remove particulate before passing to the Amersham extract system, where it passed through a further HEPA filter. The lay out of the new system is shown in Figure 1. Only one primary filter is on line at any one time. All the exhaust filters are of a safe change design and consequently a primary filter can be changed whilst the system is operating.

The New Ventilation System was designed to remove 50 litres/second of air from the cell line (equivalent to four air changes per hour).

\section{The Secondary Containment}

The general layout of the secondary containment is shown in Figure 1. It is built up from units using RWE NUKEM Modular Containment System. The containment is some $165 \mathrm{~m} 3$ in volume and is attached to the caesium facility by standard engineering fasteners.

The secondary containment was basically divided into an entry/exit, monitoring and decontamination area and an inner operational area. It comprised of the following essential features:

- An entry/exit tunnel incorporating a monitoring area and emergency shower;

- Service ports;

- Viewing windows and lighting panels;

- An airlock for waste transfers.

Personnel entered into, and exited from, the inner operational area via the entry/exit shower tunnel, which in turn is accessed from the general laboratory area. Materials are taken into the secondary containment via the airlock.

The secondary containment was normally a free breathing area and had its own dedicated ventilation system. This drew air into the containment from the surrounding areas and discharged it to the atmosphere via a dedicated primary HEPA filter; a mobile filtration unit and the building filtered space extract system. A small fraction of this air is sucked from the secondary containment by the New Ventilation System and formed the supply to the extended primary containment. The mobile filtration unit was located in a laboratory area adjacent to the secondary 
containment. The two ventilation systems did not interfere and neither interferes with the Amersham systems. The mobile filtration unit was fitted with two stages of HEPA filtration and a two stage axial fan. The system was designed to ensure that the flow velocity in any opening will not fall below $0.5 \mathrm{~m} / \mathrm{s}$. It was not intended that there should be a significant depression in the secondary containment relative to the surrounding laboratory areas. The secondary system was interlocked with the New Ventilation System such that if the latter system fails the mobile filtration unit cuts out.

\section{The Telerobotic System}

The Telerobotic System comprised of a NEATER N670SB telerobot, including auto-tool change equipment, and a supporting trolley assembly that included tool and waste storage locations, viewing systems and a cable deployment system.

The robot had a maximum $25 \mathrm{~kg}$ lifting capacity and was been designed to withstand a total integrated dose of up to $106 \mathrm{~Gy}$. An operator controlled it manually using twin joy-sticks. The operator was normally seated at a control console situated in the secondary containment but, as an alternative, could control the robot from anywhere within the containment using a portable panel that is connected to the main control desk by a substantial umbilical cable.

The robot was supplied with a selection of tools that were stored in fixed positions on the trolley. Tools could be interchanged remotely using preset routines on the Telerobotic System controller. Saw blades and the router or drill's bits were changed remotely using tongs in the Waste Posting Facility. It was unnecessary to breach either the containment or the shielding.

As remote decommissioning progressed the tooling was developed. The most significant development was the introduction of a grinder with vacuum recovery for size reducing the boxes. This allowed the contaminated dust generated from cutting to be collected at source reducing the need for operational vacuuming. Approximately $100 \mathrm{Ci}$ of activity were collected using this system during cutting.

The robot is mounted on a trolley to allow deployment and positioning of the equipment in the maintenance corridor. The trolley consisted of a basic frame mounted on four wheels. An electric motor powered all four wheels moving the trolley at a maximum speed of $40 \mathrm{~mm} / \mathrm{s}$. The robot was positioned on the trolley so that it can retrieve dropped items in front and behind the trolley.

Electrical power, compressed air for the pneumatic tools and equipment, and all control signals were supplied via cables and pipes that are bundled together to form a single umbilical cable. A cable engine and cable guide, located in the Maintenance Bay, automatically payed out and retrieved this umbilical as the trolley moves along the corridor. One of the power cables failed and was by-passed by a parallel supply cable on a separate reel mounted in a shielded box just outside the Maintenance Bay. In the event of a breakdown, the Telerobotic System could be recovered into the Bay using a manual winch operating on a wire rope attached to the rear of the trolley.

The viewing system consisted of two 2D black and white cameras with powered zoom lenses. Illumination was supplied by lamps mounted adjacent to the cameras. Each camera was mounted 
on a remotely operated pan and tilt unit that allows the camera to be orientated to suit the operation in progress. One of the cameras was mounted on an independent trolley attached to the trolley by an umbilical. The other camera, lighting unit and pan and tilt unit was bolted to the trolley. Towards the end of the remote decommissioning phase the lamps and cameras failed and additional cameras were deployed through the service holes with the lights.

The viewing station that supported the control system was located in the secondary containment. The station comprises two black and white monitors and a video recorder. These were positioned close to the operator console with controls for operating the camera zoom, camera movements and lighting.

\section{REMOTE DECOMMISSIONING OPERATIONS}

The remote decommissioning operations began in 1997 and involved the use of the above plant to remotely decommission the cell line to a condition where man entry and manual decommissioning were justified on ALARP (As Low As Reasonably Practicable) grounds.

The overall strategy applied to the remote phase involved removing the back from one cell and then removing the majority of its contents before breaching the next cell. Work started with the least active cell first. This arrangement kept the contamination levels inside the facility as low as possible and also allowed the robot a "shake down" period after it was moved from the mock up, from another site, to the facility proper. Once in the facility the Telerobotic System could not be run without exposing it to activity. If, as happened, the move induced faults in the robot the lower initial activity meant that the contamination levels in the Maintenance Bay were initially fairly low, thus making any necessary repairs easier.

The main phases of the work are summarised below.

- Removal of the accumulated waste from the boxes. All the box contents were removed during this part of the work. Dose rates as high as $3,000 \mathrm{R} / \mathrm{h} \gamma$ were observed on some of the waste cans and some $2,500 \mathrm{Ci}$ of ${ }^{137} \mathrm{Cs}$ activity were removed. Despite the removal of the waste, contact dose rates as high as $2,500 \mathrm{R} / \mathrm{h} \gamma$ remained in some areas. This was thought to be due to the presence of dust and small pellets.

- Vacuuming the boxes to remove loose contamination. Vacuuming the accessible areas removed a further $1,000 \mathrm{Ci}$ of ${ }^{137} \mathrm{Cs}$. The removal of the waste and the initial vacuuming typically reduced the original contact dose rates by an order of magnitude and the new contact dose rates lay in the range $50 \mathrm{R} / \mathrm{h} \gamma-200 \mathrm{R} / \mathrm{h} \gamma$.

- Removal of the fibre glass boxes removed a further $500 \mathrm{Ci}$ of ${ }^{137} \mathrm{Cs}$. This typically reduced the contact dose rates by a further order of magnitude with the exception of one area where there was known to have been liquid spills during operations. The dose rates here were largely unchanged.

- Remote scabbling of accessible concrete areas reduced general contact dosreates to 100 'smR/h $\gamma$.

- Steel plates were removed to remove contamination where liquid had seeped into the concrete below. This allowed further scabbling to depths of $150 \mathrm{~mm}$ to reduce doserates down to levels acceptable for man entry. Remote decontamination of the plinths and the maintenance corridor floor removed approximately another $100 \mathrm{Ci}$ of ${ }^{137} \mathrm{Cs}$. 


\section{MANUAL DECOMMISSIONING EXPERIENCE}

The remote decommissioning work was completed in 2001 . The final task was to carry out a thorough radiological survey of the facility. Once this was completed the Telerobotic System was removed to gain access to the maintenance corridor.

The Telerobotic System was decontaminated so that it was disposed of as LLW or non-active waste. The majority of the decontamination was vacuuming to remove dust that was trapped on the trolley under its covers.

The main phases of the manual decommissioning work are summarised below.

- Vacuuming the facility to remove loose contamination. This was generally radioactive dust from the size reduction operations. The Telerobotic System had thoroughly vacuumed the facility before it was removed and the facility appeared to be relatively dust free. However man entry with direct vision showed a different picture. A significant amount of the radioactive dust was removed, approximately $5 \mathrm{Ci}$. This reduced doserates by a factor of 10 to a few 10 's of $\mathrm{mR} / \mathrm{h} \gamma$.

- Hot spots were removed by surface abrasion. Hot spots had been covered with lead at the end of the remote phase. Each hot spot was uncovered one at a time and the area decontaminated before moving onto the next. This in itself did not reduce doserates further but lead that was covering hotspots could be removed. One significant hot spot remained on a $25 \mathrm{~mm}$ thick steel plate of $6-700 \mathrm{mR} / \mathrm{h}$ over a large area. The steel was grit blasted but the doserate did not reduce. It was apparent that liquid from a known spill in this area had seeped under the plate, and possibly the two below it, and that they had to be removed.

- The plates 3 plates each weighing $175 \mathrm{~kg}$ were size-reduced in-situ, decontaminated and disposed of as LLW. Care had to be taken not to disturb adjacent steel work that was structural.

- Surface abrasion was used on all areas to remove paintwork and some concrete. Peelable coating was then used to remove small loose particulate. This reduced doserates to less than $10 \mathrm{mR} / \mathrm{h} \gamma$.

- As the steelwork and concrete was structural, only limited amounts could be removed without affecting the structure. The structure was also integral to other operational facilities close by. Hence no further removal of material was carried out. Free breathing conditions were achieved using tie-down paint and relatively high areas of fixed contamination shielded with lead sheet to reduce doserates to less than $1 \mathrm{mR} / \mathrm{h} \gamma$. 


\section{OPERATIONAL EXPERIENCE}

\section{Telerobotic System and Mock-up}

Prior to its insertion into the facility the Telerobotic System was extensively tested in a mock up of the real system. The tests carried out were based upon information about the difficulties that were expected to arise. This information was gleaned from a range of historic documents. As with many an old plant the documentation was somewhat patchy. The decommissioning arrangements were therefore designed to be flexible. This flexibility has proven to be an asset and in particular has meant that unforeseen difficulties could be tackled in a safe manner. Experience however confirms the basic fact that for overall efficiency there is no substitute for prior knowledge.

All the tools supplied with the robot have proved of considerable value. The vacuum cleaner was however of particular value because of two reasons. There were hundreds of small pellets and capsules that were dropped during manufacture which had to be recovered. Also cutting the glass-fibre containment boxes produced significant amounts of contaminated dust that had to be recovered. In total approximately $40 \mathrm{TBq}$ of loose activity was recovered using the vacuum.

The cleaner was wholly contained within the primary containment so that its operation poses no radiological hazards. Considerable effort has gone into developing the optimal configuration. For operational reasons its construction is divided into two parts, a dust collection and a fan unit. Dust and small particles are picked up using a flying hose and the two units are connected together using a second hose. The hoses are sized such that it is impossible to assemble the unit the wrong way round. Such a misconnection would have no safety connotations but would be operationally inconvenient. The dust collection unit is made from a standard waste can and thus disposable. When full it is posted out from the facility in the same way as other waste cans.

There were a number of failures of the remote equipment but all have been associated with the peripherals rather than the robotic arm itself. The umbilical cable has been a particular point of weakness. In addition, the lights and cameras originally supplied proved very difficult to replace after extensive use and an alternative arrangement was substituted.

\section{Viewing}

Radiation tolerant cameras can be expensive. They are however the eyes of a job such as this. Operators spend many hours looking at the images on the screen. It is therefore cost effective to provide them with the best possible image quality. A good sharp image makes it easier for operators to deliver the required high levels of manual skill and also reduces the strain in so doing. A fundamental weakness of the robotic viewing system is that it is one sided in that it can only view the work from the maintenance corridor. This limitation means that only highly skilled technicians could carry out the work.

In some cases, where the cell front viewing windows were not too seriously crazed, it was possible to look into the cells from the front. In these cases the operator could gain an all round view of the object on which he was working and significantly faster progress was possible. 


\section{Remote Packaging of Waste}

Minimising the volume of waste during decommissioning can significantly reduce the overall cost of a project. This was particularly important for this project as all waste was expected to be Intermediate Level Waste. During the pre-works a can crusher was installed in the Waste Posting Facility to reduce the volume of 2.2 litre waste cans that were known to be in the facility. Due to the limited space no other equipment could be installed at the time. After the first cell was decommissioned the space was used to install further size reduction equipment. The cell face tongs were re-furbished to operate the equipment. This allowed the Telerobotic System to continue as planned, whilst at the same time the waste was size reduced further. This gave better packing factors and thus less volume of Intermediate Level Waste. A waste transfer arm was also installed in the cell face allowing the waste to be transferred to the Waste Posting Facility without interfering with the Telerobotic System size reduction operations.

\section{Maintenance Facilities}

The sizes of the Maintenance Bay and to a lesser extent that of the Waste Posting Facility were dictated by the limited space available. In the case of the Maintenance Bay the space is both the maximum that realistically could be made available and near the minimum that is acceptable. The small size has little effect on day to day operations. However it is believed to have contributed to the umbilical failures because it was necessary to store the cable in a locker with many tight bends rather than wound around a drum of relatively large diameter. The gentler curves associated with the latter arrangement would have fatigued the cable less.

The congestion also posed problems when it proved necessary to enter the bay in order to effect a repair. It was difficult to decontaminate the area to a radiation level where man entry became possible and the work was further slowed down because the operator had to cope with the congestion. In practical terms there was little that could have been done to alleviate the situation. If more space had been available a larger facility and more remote decontamination facilities would have been desirable.

In line with the rest of the facility the Waste Posting Facility is fitted with tongs. Their limited ability of manoeuvre is well known. In future work it would be worth considering the possibility of supplying one or more mini Master Slave Manipulators. Their greater flexibility could justify their greater cost. The currently perceived wisdom in decommissioning circles appears to be that if manipulators are not already present they are not usually worth installing. Our experience would suggest that this conclusion is not necessarily axiomatic.

\section{Staff and Dose}

An in house team of decommissioning technicians was used to decommission the facility. Each one had completed a mechanical apprenticeship and supplemented this with several years of decommissioning experience. Their knowledge of tooling and size reduction in a nuclear environment gave longevity to equipment and allowed equipment and techniques to be adapted when unforeseen tasks arose. 
Dose to operators has been kept within $5 \mathrm{mSv}$ per year for all of the decommissioning team. The $5 \mathrm{mSv} / \mathrm{y}$ figure is now commonly used as a Dose Restraint Objective in the British Nuclear Decommissioning industry. This may appear to be easily achievable for remote decommissioning projects. However in the circumstances that we encountered this was not the case. With operational plant close by and the gradual increase in doserate from the primary vent system pipework between the pre-filter and Primary HEPA filter the background doserate was just over $2 \mu \mathrm{Sv} / \mathrm{h}$. Working a nine hour day over 220 working days this equates to approximately $4 \mathrm{mSv}$. This only leaves a small allowance for other work such as changing HEPA filters, handling waste packages and non-routine maintenance which are significant when dealing with large amounts of activity such as this.

\section{SAFETY MANAGEMENT AND RELATED DOCUMENTATION}

The Nuclear Installation Inspectorate licenses Amersham. One consequence of this is that Amersham retains overall responsibility for the safety of the operations carried out by its contractors. All safety related documents are therefore written to conform with and cleared through the Amersham system. The systems in place there allow:

- Contractors sufficient freedom to utilise their own skills.

- Amersham to process documents in an effective manner contributing their skills not only to the management of safety but also to the effective execution of the project.

- Provide the opportunity for contractors to manage safety in their own way whilst at the same time ensuring that Amersham's requirements are met.

A schematic diagram indicating the relationship and extent of the safety documentation that has been produced for this project is contained in Figure 2. The top level, Level 1, safety document, the Stage 1/2 Safety report was the original overarching Safety Document written in the planning phase. It set out the overall objective, defined the radiological end point and justified the general approach that was to be deployed. In turn it identified the additional documentation that would be required. The document was peer reviewed and endorsed by the Amersham Nuclear Safety Committee.

The report also confirmed the need for the additional equipment described above and concluded that each new item of plant would need its own more detailed, Level 2, safety document, these were called Stage 2 (New Plant) Safety Report and a corresponding Stage 3 (New Plant, Commissioning) Safety Report. The Stage 2 Reports basically described the plant, justified the approach and set out how it would be commissioned. This was written and approved before installation on site began. The corresponding Stage 3 Reports explained how the conditions set out in the Stage 2 Report had been met.

Finally, the Stage 1/2 Report concluded that a Stage 3 (Pre Commencement) Safety Report for the complete project would need to be prepared, peer reviewed and then approved by the Safety Committee, prior to the issue of an Authority to Proceed (ATP). 
By mutual agreement the operations were divided into two phases:

- Phase A, embracing the remote decommissioning and decontamination operations

- Phase B, covering the corresponding manual operations.

The Method Statements, level 3, referred to in Figure 2 are more detailed instructions that translate the principles in the Safety Report into detailed instructions for the operators. These were reviewed and approved by Amersham before work could commence. They could refer to RWE NUKEM Standard Operating Procedures, level 4, that were audited by Amersham but did not require individual approval.

\section{Changes to Safety Documentation}

Inevitably during decommissioning operations some of the methods need to be changed as a result of experience and/or the availability of new information. These changes are controlled by Deviations. Deviations arise at three levels*. They are:

Level i This level covers:

- Minor deviations from the Safety Case that do not change the safety systems.

- Deviations whose consequences are within the scope of the safety case but outside the current working method statement.

Level ii This level covers deviations that are either within the Safety Case but not covered by the method statement or involve a change to the Safety Case involving minor changes to safety systems.

Level iii This level covers all the more major changes and involves formal changes to the Safety case.

The approval route for a Deviation is dependent on the Level of the proposed change. Basically Level i lies with the project subject to subsequent report to Amersham. Level ii involves formal approval by the appropriate member of Amersham staff. Level iii involves formal consideration and approval under the Amersham safety system.

There were 46 Deviations to the original Safety Case. 34 During the remote phase and 12 during the manual phase. None were above Level ii.

\section{CONCLUSIONS}

RWE NUKEM safely decommissioned a former Caesium-137 sealed source production facility owned by Amersham.

The majority of the work was carried out robotically including all size reduction of the plant and removal of over $99.9 \%$ of the activity.

\footnotetext{
* The 3 levels of these deviations do not relate to the levels of pre-work safety documentation discussed above.
} 
WM'03 Conference, February 23-27, 2003, Tucson, AZ

$2300 \mathrm{~kg}$ of intermediate level waste containing approximately $4000 \mathrm{Ci}$ of $\mathrm{Cs} 137$ have been removed remotely from the facility.

The site is now available for future production requirements.

\section{ACKNOWLEDGEMENT}

RWE NUKEM gratefully acknowledges Amersham plc's permission to publish this paper. 


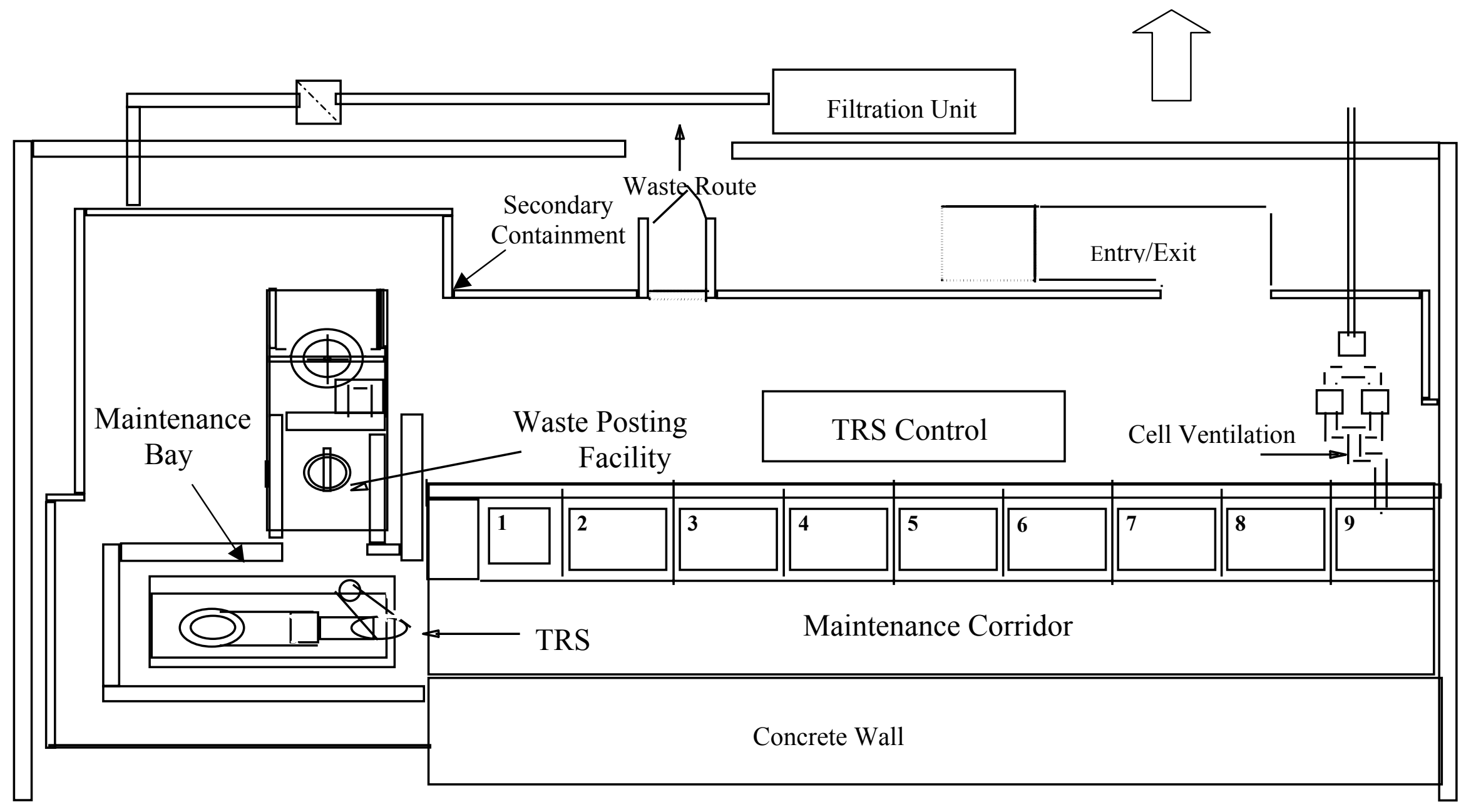

Fig. 1. Plan of the facility during the robotic decommissioning phase 


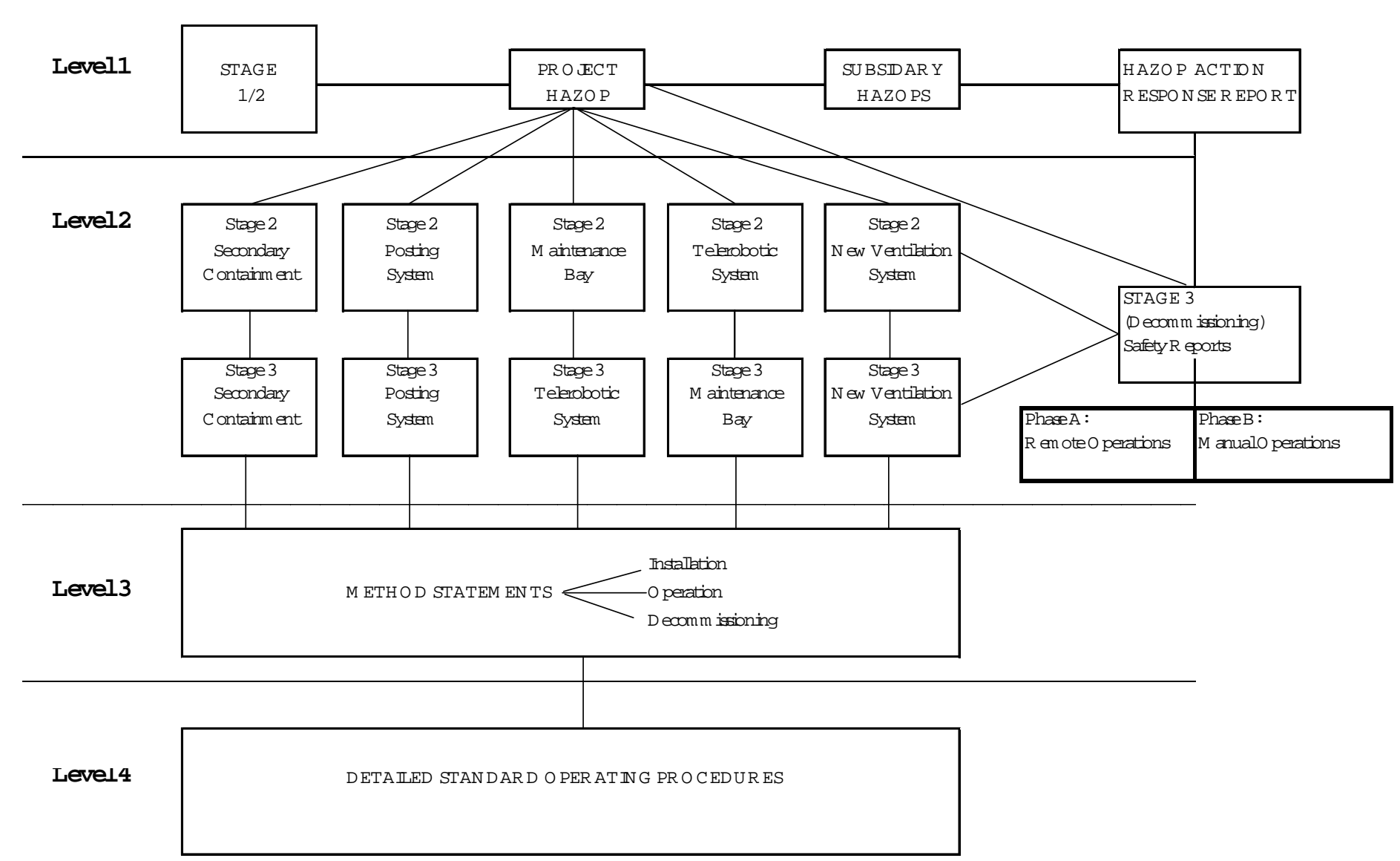

Fig. 2. Schematic overview of the safety documentation produced 